\title{
Teaching science through designing technology
}

\author{
Mai M. Sidawi
}

Published online: 11 December 2007

(C) Springer Science+Business Media B.V. 2007

\begin{abstract}
This paper is a review of the literature related to teaching science through designing technology. The premise of this method is that designing technology presents the students with the context through which they can apply the science concepts they learned and thus enhancing their understanding of these concepts. Despite the promise of this method, teachers attempting it were faced by many challenges such as: (1) teachers did not have a grasp of the complex relationship between science and technology and assumed that technology was simply applied science, (2) the students were not able to transfer their learning of science to designing technology, (3) teachers did not have a deep understanding of the design process and tried to teach it as a linear, context-free process without regard to the context of the problem. The purpose of this paper is to extract from the literature a better understanding of teaching science through designing technology and the elements that teachers need to satisfy in order to increase their chances of successfully implementing this method in the classroom.
\end{abstract}

Keywords Science $\cdot$ Technology $\cdot$ Education $\cdot$ Design $\cdot$ Knowledge transfer

\section{Overview}

Despite the fact that before the 1950s, the majority of technological inventions and innovations did not rely on scientific theory for their development, scientific theory is becoming increasingly the foundation of technological development (Laporte and Sanders 1993). This connection between science and technology inspired science educators to ask themselves "whether technology-centered activities afford a learning environment that scaffolds students' learning of science" (Roth 2001, p. 768). Leading national organizations of science education responded to the need of addressing the relationship between science and technology when shaping science standards and curriculum. The American Association for the Advancement of Science (AAAS) and The National Research Center

M. M. Sidawi ( $₫)$

The Math Forum @ Drexel, 3210 Cherry St., Philadelphia, PA 19104, USA

e-mail: sidawim@drexel.edu 
(NRC) introduced the relatively new notion of science literacy (AAAS 1989; NRC 1996). The term "intrinsically includes understanding technology" (Cajas 2001, p. 716).

According to Cajas (2001), science literacy became the common goal that represented the first formal interaction between science education and technology education in the United States. Through the conception of science literacy, the AAAS $(1989,1993)$ "broke with old disciplinary conceptions of science and recommended that all students learn key technological ideas such as design, control, and systems as well as the relationship between science and technology. It called for understanding relevant concepts about specific technologies (e.g., materials, energy, communication, and agricultural technologies)." (Cajas 2001, p. 718).

Realizing the need for new methods in teaching science, the National Research Center (NRC) developed the "new ambitious" (Edelson 2001, p. 355) National Science Education Standards (NRC 1996). The standards put pressure on science educators to teach more content and at the same time engage the students in authentic scientific practices. The standards condemned the traditional emphasis on memorization and recitation and called for teachers to foster “'deep' and 'robust' conceptual understanding” (Edelson, p. 355).

Traditionally, science educators have seen content and process (inquiry) as competing priorities and claimed that satisfying the new standards and balancing between the two priorities was an unachievable goal (Edelson 2001). But under the pressure of the new standards and due to the poor performance of the American students in science, the need for breaking away from the old ways of teaching grew stronger. This led some to see designing technology as an approach that can integrate content and process for the learner (e.g., Crismond 2001; Edelson 2001).

\section{Teaching science through designing technology}

When teaching science through designing technology the students work towards finding a solution to open-ended problems. The problems can have a variety of foci such as electrical and computer control, food, structures, textiles, and materials. Through the pursuit of a solution to these problems, students experience "the three aspects of developing, planning and communicating ideas; working with tools, equipment, aspects of developing, planning and communicating ideas; equipment, materials and components to make quality products, and evaluating processes and products (Qualification and Curriculum Authority (QCA) 2001).

While designing technology, students are expected to draw on their knowledge of other areas of the curriculum to develop and improve their design. In the case of science, designing technology provides the context through which students can apply their scientific knowledge whereas science provides part of the conceptual knowledge needed for the students to develop their design.

In the literature, teaching science through designing technology has been called by so many names: teaching of science "through activities that emphasize design and technology" (Seiler et al. 2001, p. 746), "science-through-technology curricula", "learning in technology-centered classrooms", learning "science by designing technology" (Roth 2001, p. 768) and applying science knowledge for the purpose of "problem solving through technology" (p. 39, Rowell et al. 1999). All the above terms describe the same activity which is: students learning science through 'designing and making' technology.

In the literature, the term 'designing technology' is usually used to indicate that the students will be both designing and constructing their designs. Hennessy and McCormick 
(1994) used a more explicit term and called the activity 'design and make' technology. This is different than the design-without-make process. The omission of the 'make' stage can be a result of the teacher's lack of understanding of the value of the making process and his or her reluctance to allocated it the needed time (Stein et al. 2002). Also, the term Design and Technology is used frequently in the literature to describe the activity of students designing technology.

\section{Teaching science through designing technology and the perception of technology}

Teaching science through designing technology requires a realistic perception of technology and its relationship with science. A teacher who perceives technology as 'computers' can see this integration as simply using computer software for data keeping and manipulation. A teacher who perceives technology as 'applied science' can undermine the fact that technology entails its own technological knowledge.

Most students think of technology as a product not a process. Such perception can influence their learning of technological concepts and processes. If students think of technology as 'hi-tech' they may seek solutions to technological problems that incorporate 'hi-tech' features and ignore other more relevant and appropriate solutions (Jones 1997). Also, students' limited concepts of technology may affect the teacher's own perception of technology education, especially if the teacher's understanding of the nature of technology was fragile (Jones 1997). Thus, a successful designing technology experience has to be built on a realistic understanding of technology in each situation.

According to Roth (2001), designing technology is described as the "entire set of activities that lead from initial vague ideas ... to the construction of initial prototypes that are tested and to the final working model" (p. 778). Within these activities, technology is more than using computers as frequently thought (Cajas 2001). Technology has a broader definition that includes "the means by which people mediate between nature and themselves" (Hansen 1997, p. 112). Technology is the product, including all the knowledge that its creation entails, through which people utilize their resources on earth so that they can first survive and then move on to raise their standard of living. For example, "The making and shaping of bronze by ancient metallurgists, the extraction of dyes and mordants for coloring fabrics, the heating and cooling of a mixture of kaolin and feldspar to make Chinese porcelain" (Gardner 1997, p. 19) are all examples of technology. Therefore, from this perspective, technology can be seen as an "artifact, knowledge, and social practice" (Cajas 2001, p. 716).

\section{Teaching science through designing technology and the relationship between science and technology}

When teaching science through designing technology it is important to define the relationship between the two domains. In the past, the dominant view was of technology as applied science. The problem with this view is that it ignores the fact that has been emphasized by learning theorists in the technology education community: technology entails its own conceptual knowledge that is not encompassed by scientific knowledge (e.g., Johnson 1997; McCormick 1997). Thus, it takes more than scientific concepts to develop a technological artifact. Roth (1995) noted that tool-related practices such as 
sowing, glueing and hammering were part of the body of knowledge that was appropriated in the Design and Technology classroom.

Rowell et al. (1999) indicated that the perception of technology as applied science stems from the assumption that "knowledge of science precedes development of technological knowledge" (p. 38). They pointed out that although this view has since been "subjected to challenge by both historical studies and by philosophical analyses" (p. 38), most educators they interviewed perceived technology as applied science. The problem with this perception is that it leads to the erroneous assumption that all technological artifacts are based on scientific principles. This assumption was extensively refuted by the members of the technology community (e.g., Cajas 2001; De Vries and Tamir 1997; Gardner 1997; Roth 2001).

The debate regarding the relationship between science and technology has intertwined with the debate regarding the relationship between thought and action and knowledge and applying knowledge. In the Renaissance era, engineers such as Leonardo da Vinci and Francis Bacon believed thought and action to be inseparable and accordingly, science and technology were seen as interactive domains. Science pursued the knowledge of the natural world and thus facilitated controlling it and harnessing it to serve mans' will through technology. Under such a premise, cognition and practical knowledge were bonded (Layton 1991).

However, contrary to the predictions of Renaissance engineers, this interactive relationship between science and technology did not last. The Renaissance engineers expected a "simultaneous and unified scientific and technological revolution" (Layton 1991, p. 44), this revolution did not happen (Layton 1991). To the contrary, science and technology embarked upon "processes of development which followed separate, though inter-connecting, paths" (p. 45). The industrial revolution in Britain came a century after the scientific revolution and its origins owed little to scientific knowledge (Russel 1983, p. 99, as cited in Layton 1991).

The separation of the path between science and technology was driven by the difference in the goal behind each discipline. Whereas the science community valued knowing, the technology community valued doing. Even when scientists, as often happened, "began their investigation from some point of technological interest (e.g., the observation by mining engineers in the 16th century that 'suction pumps' could not raise water to a height greater than about 30 feet), their goal was not improved performance of the technological artefact, but an understanding of its principles leading to general theory (e.g., the subsequent work of Galileo's pupils, Torricelli and Viviani, together with Pascal, yielded a general theory of pneumatics)" (Layton 1991, p. 45).

Moreover, in their pursuit of developing their Scientific Laws of Nature, scientists such as Newton and Galileo created an idealized version of reality. In the ideal world, where these laws apply, points occupied no space, material bodies had perfect rigidity, fluid media was untroubled by turbulence and eddies, and space was homogeneous and isotropic (Layton 1991). Technologists who could not transfer this abstracted world to their applied domain struggled with real-life questions such as "why large machines, built to the same geometrical proportions as smaller and operationally effective ones often failed" (Layton, p. 45). Scientists such as Galileo failed to answer such questions because in their ideal word, the same laws of mechanics described events on both terrestrial and celestial scale (Layton 1991).

Despite their pursuing different goals, the science and technology communities maintained a two-way interaction that affected them both. Technological instruments such as clocks, thermometers, barometers, and voltmeters "allowed greater precision and 
standardization of scientific data" (Layton 1991, p. 45). At the same time, general scientific theory was directed by an interest in solving technological problems. However, when engineers put the scientific theory to the test of application, it often failed. For example, the ships that the English built based on Newton's opinion of the most advantageous section, failed to sail as well as those built according to the rules of experience (Klemm, 1959, as cited in Layton 1991). Accordingly, throughout the 18th century, the communities of science and technology remained to a large degree distinct with science mainly dealing with abstract knowledge that was manipulated and communicated through symbols whereas technology dealt with direct application and emulation (Layton 1991).

By the arrival of the 19th century this distinctive relationship flared into battles where technologists highlighted the inconsistencies between 'theory' and 'practice' (e.g., Hunt 1983; Bud and Roberts 1984; Kline 1987, as cited in Layton 1991). On the other hand, scientists proclaimed science as superior to technology for its role in generating knowledge and theory they believed to be readily available to technologists to use in solving their problems and improving their devices (Whewell 1834, as cited in Layton 1991). The underlining assumption behind that hierarchal relationship was that technology was 'applied science'. Such assumption was disputed for being simplistic and not able to capture the complex factors that were involved in taking the results of a laboratory-scaled experiment and applying it to the production of an acceptably-priced, high-quality, marketable product in hazardous industrial conditions. Producing a technological artifact involved environmental, economic, and legal factors that went beyond the science (Travis 1990, as cited in Layton 1991).

Moreover, not all technological discoveries were science-based. De Vries and Tamir (1997) noted that "historically and methodologically, it can be shown that technological progression can only partially be accounted for by the use of scientific knowledge" (p. 5). The story of the development of the electric motor and dynamo cannot be simply explained in terms of the application of the laws of physics (Gardner 1997). Other examples of technological products that have not been created based on scientific knowledge are: "the making and shaping of bronze by ancient metallurgists, the extraction of dyes and mordants for coloring fabrics, the heating and cooling of a mixture of kaolin and feldspar to make Chinese porcelain" (Gardner, p. 19). Accordingly, describing technology as "applied science' was described to be "superficially attractive but fundamentally incorrect" (McCormick 1997, p. 15).

This does not imply that there were no technological products that were actually an application of scientific discovery. Röntgen's discovery of X-rays quickly led to their practical application in medical diagnosis and later in metallurgy and material science. The work of scientists such as Volta, Ampere and Faraday provided the foundation for what is today called electrical engineering. But this cannot simply mean that we can generally describe technology as 'the fruit that fell from scientific trees' (Gardner 1997).

According to Gardner (1997), technological products were more of a result of human beings' interaction with objects and materials in the world, understanding these materials, thinking about them, gaining experience with them, and then using them to make things. This desire "to use resources intelligently to meet human needs" (p. 14) is the motivation behind creating all technological products whether they are based on scientific knowledge or not.

By the mid-19th century, the arising engineering departments in universities helped in bridging the gap between 'theory' and 'practice'. Engineers realized that abstract science was not readily available to be applied to technology. They needed to create a new body of knowledge to serve as "an intermediary between abstract science and practical action" 
(Layton 1991, p. 49). Hence occurred the development of 'engineering science' that enhanced the applicability of science by coupling it with the technological knowledge component that was needed for the transition from the abstract to the applied.

When teaching science through designing technology, the question arises as to how to relate the two disciplines. Science education is not only about the facts or content of science. True science literacy is about experiencing the practices of scientist such as "designing and carrying out investigations in a replicable way, accurate observation and measurement, informed use of evidence to make arguments, explanation using scientific principles, working in a team, communicating ideas, and so on. In fact, scientists and designers practice many of the same skills" (Kolodner 2002).

The teachers' understanding of the nature of the relationship between science and technology can influence the teaching strategies they employ. When teachers for example perceive technology as 'applied science' they erroneously assume that all technological artifacts are based on scientific principles.

According to Layton (1993), the benefits of a strong relationship between science education and technology education can flow in both directions. For example, science can be a resource to technology when students choose the appropriate materials for their designs. The students can look for the properties of these materials, such as thermal conductivity, in scientific tables. Also, the students may need to conduct a small-scale scientific experiment to answer questions such as "which material can best repel water under these conditions?" The students' knowledge of how to define the affecting variables and how to control for each variable can be borrowed from science and help the students in their design of technology. In fact, this "method of establishing facts by carefully controlled experiments is an important contribution of science to technology" (p. 44).

On the other hand, science education can benefit from technology education which can provide the context through which students can articulate their science knowledge with practical action. "This articulation of science with practical action would help to project a more authentic view of the nature and creative foundations of scientific knowledge" (Layton 1993, p. 65).

Layton (1993) argued that in order for students to be able to articulate their scientific knowledge in action, scientific knowledge has to be reshaped, contextualized and reformed. The scientific laws taught at school are usually simplified by constructing them in an ideal world where beams are perfectly rigid, levers rarely bend, and truly spherical balls roll down an inclined plane unhampered by friction. This process of simplification of real-life complex situations is what Layton called "decontextualization" or "reductionism" (p. 59). In order for students to be able to use such scientific knowledge when they design technology, this process of simplification has to be reversed by "recontextualizing" (p. 59) knowledge by building back into it some of the real life complexities.

In fact, Layton (1993) stated that this process of recontextualization is a missing link in science education which a partnership with technology education can provide. According to Layton "much recent research on children's learning of science has been premised on a view of learning as a process of knowledge construction which starts from prior knowledge-preconceptions, intuitions, alternative frameworks - that students bring to their lessons. Consideration of the relationship between science education and technology education suggests an additional process is important. This involves the deconstruction and reconstruction of the scientific knowledge acquired in order to achieve its articulation with practical action in technological tasks" (p. 59).

For example, students who learned Hooke's law of elasticity and try to apply it on a rubber band subjected to a load become aware of a certain load beyond which the rubber 
breaks and Hooke's law does not apply. When the students reconstruct their science knowledge to account for the issues presented by the context of the design problem, they are able to display their scientific knowledge in a useful practical form that can be applied to solve real life problems.

The fact that both participants of the partnership between science education and technology education benefit, leads to a strong basis for their symbiotic relationship (Layton 1993). However, in order to maintain such a healthy relationship, some logistical issues such as coordination between teachers, scheduling and allocation of resources may prove to be a challenge. Also, a deep understanding of the differences between science education and technology education have to be clearly understood.

According to Layton (1993), the major difference between "doing science" (p. 48) and "doing technology" (p. 48) is that doing technology is subject to certain constraints that can make a solution to a certain problem unacceptable. When scientists solve a problem they are only concerned with whether the theory or hypothesis "fits the facts" and "contextual preferences external to science play not part" (p. 48). In contrast, technologists are restrained by an array of external criteria that govern the acceptability of their solution. First of all, the technological product they produce has to be functional. In addition, the materials it is made up of cannot be costly or dangerous to human life or health, and the production process cannot be harmful to the environment. Students have to be made aware of such constraints when they design technology.

\section{Pedagogical strategies in the design and technology classroom}

The potential promise of using designing technology as a pedagogical strategy for teaching science lies in the fact that it encompasses four pedagogical strategies that have been shown to have positive effect on the learning of students: (1) collaborative learning (e.g., Johnson and Johnson 1991), (2) reflective learning (e.g., Brown 1992), (3) contextual learning (e.g., Roazzi and Bryant 1992), and (4) project-based learning (e.g., Brown et al. 1989). These four strategies relate to the social aspect of learning, the learner, the learning environment, and the learning task, respectively. According to Johnson (1997), "Instruction could be developed for each of these elements independently, although combining these elements will result in a more powerful learning environment" (p. 170).

Collaborative learning in the design and technology classroom

As for the social aspect of learning, the positive impact of collaborative learning on the performance of students has been proven by many research studies (e.g., Johnson and Johnson 1991). In fact, understanding the nature of the mind and the way we learn underscored the fact that learning is a social act (Rogoff and Lave 1984). However, by employing pedagogic strategies that so far have concentrated on individual learning "most science education has not realized or made use of the potential that lies in the social nature of knowing and learning" (McGinn et al. 1995, p. 164).

Teaching science through designing technology can support collaborative learning. Researchers have noted that the Design and Technology classroom, where students mostly work in groups to design a solution to an open-ended problem, provides a rich context for practicing collaborative learning (e.g., Johnson 1997). 
The collaborative learning in the Design and Technology classroom is shaped by many factors such as the common task that the class is performing, the resources and practices that the students share, and the pattern they follow in sharing their ideas. Within such a classroom, interactions are taking place continuously when sharing tools, at workshop stations, in groups and within groups. Learning in the class is no longer individual and the class goes through a collective knowledge building (Scardamalia and Bereiter 1994).

For example, in the Design and Technology classroom, students regularly checked with their peers to make sure that their ideas conformed with the classroom norms (McGinn et al. 1995). Through this sharing of ideas, they negotiated a common goal and regulated their behavior to fit the common practices of the class (Roth 1995). During the designing process, students redefined their problems and extended the original conditions of their tasks. Students who were physically isolated from the group (by working in the hallway) did not participate in this process of collective knowledge building and thus their problems were entirely different (Roth 1995).

Reflective learning in the design and technology classroom

Reflective learning focuses on the learner. It calls for the need of the learners to be aware of their own thinking (Johnson 1997). By training the students to reflect, evaluate and critique their own knowledge, educators believe that students can take control of their own learning and shift from being passive to active learners (Brown 1992). The nature of learning in the Design and Technology classroom supports reflective learning. Through their design drawing, their technological artifacts, and their presentations, students externalize their ideas and open them for critique and inspection (Roth 1995).

Contextual learning in the design and technology classroom

Whereas reflective learning focuses on the learner, contextual learning focuses on the environment of learning. The interest in understanding the influence of the context on learning started in the 1980s (Brown 1992). Research on reflective learning in the 1970s has concentrated on developing strategies to train the students to be reflective learners. However, this research led to the conclusion that there cannot be a successful decontextualized approach to this strategy and hence the importance of the context of learning dominated research in the 1980s (Brown 1992).

Based on these research findings, new theories of cognition were developed. Based on these models, "cognition was modeled as arising from the interaction of human agents with their setting" (McGinn et al. 1998, p. 814). These models of cognition were a result of numerous studies that followed people in their everyday life and recorded the way they learned (e.g., Carraher et al. 1985; Lave 1988). The findings of these studies showed that people in their everyday life solved the problems they faced within the framework of their context. For example, a Weight Watchers dieter who needed to measure three-quarters of two-thirds of a cup of cottage cheese "filled a measuring-cup two-thirds full of cottage cheese, dumped it out on the cutting board, patted it into a circle, marked a cross on it, scooped away one quadrant, and served the rest" (Lave 1988, p. 165). Thus, the dieter saw the problem and its resolution in terms of the elements of its context, the measuring-cup, cutting board, and knife (Brown et al. 1989, p. 35). "At no time did the Weight Watcher check his procedure against a paper and pencil algorithm, which would have produced 3/4 
cup $\times 2 / 3$ cup $=1 / 2$ cup. Instead, the coincidence of the problem, setting, and enactment was the means by which checking took place" (Lave 1988, p. 165). This example demonstrates the connection between cognition and context.

Teaching science through designing technology is perceived by some as an answer to the need for engaging the students in tasks that help them learn and apply science in realworld contexts (e.g., Crismond 2001). This need was prompted by the recognition that "a rich learning environment filled with authentic problems and real situations is critical for developing intellectual skills" (Johnson 1997, p. 170). Researchers have long criticized the school environment for lacking relevance and for being divorced from reality (e.g., Hennessy and McCormick 1994). For example, Brown et al. (1989) described how math students used "school-based cues" (p. 36) such as the position of the problem in the book to solve math problems. Such "extremely fragile" (p. 36) strategies were not useful outside the school and could only be applied within the "extremely specialized" (p. 36) school situation.

Research on design and problem-solving processes in general lead to the conclusion that such processes are context related. There has been little empirical evidence that supports the idea of a general problem-solving process that can be applied to a variety of contexts and subject areas (Hennessy and McCormick 1994). To the contrary, "research shows that what problem-solvers of all ages in everyday and workplace situations actually do and know depends on the context in which they are asked to work" (Hennessy and McCormick, p. 99). In the case of the Design and Technology classroom, students who failed to develop certain discursive practices in response to teachers' prompting, were able to do so in response to emergent problems that they faced during their design. For example, several students who designed bridges as a part of a unit on civil engineering did not use triangles to support their bridges despite their teachers' encouragement to do so. These students decided to use triangles in their designs only when faced with the problem of structural weakness in their bridges (Roth 1995, p. 497). This supports the relevance of context to problem-solving.

Project-based learning in the design and technology classroom

Project-based learning focuses on the learning task by building the learning around an activity. This approach is important because it provides a link between knowing and doing. Just as we cannot see knowledge as abstract and detached from context, we also cannot separate knowing from doing (Brown et al. 1989). This model of learning recognizes that "knowledge isn't something we pour from one vessel (a teacher) into another (a student)" (Sorrohan 1993, p. 48). Instead, knowledge is recognized to be "similar to a set of tools. They can only be fully understood through use, and using them entails both changing the user's view of the world and adopting the belief system of the culture in which they are used" (Brown et al. 1989, p. 33). Brown et al. argued that "it is quite possible to acquire a tool but to be unable to use it" (p. 33). Thus, they believed that knowing and doing have to be "interlocked and inseparable" (p. 35) for learning to occur. This implies that students should not be taught abstract knowledge without providing them with a context where they can apply it.

Learning in the Design and Technology classroom is project-based. In that classroom, learning is focused around an activity that requires sustained thinking about specific problems over long periods of time. This activity motivates the students, involves considerable amounts of creativity, decision making and problem-solving (McCormick 1997). 
In the Design and Technology classroom there is no separation between doing and knowing and their relationship is no longer based on a "inferior/superior" (McGinn et al. 1995 , p. 164) basis. Through the activity of design, with its social and physical context, students co-produce knowledge and the learning is embedded in the activity (Brown et al., 1989). They respond to problems as the problem emerge during the design process. They develop discursive practices and tool-related practices. The classroom forms a community of learners that collectively builds knowledge. Progress occurs in the community when we notice changes in the existing practices and resources of a community and tradition that supports the practices (Roth 1995).

How do students learn science through designing technology

Roth (2001) conducted a series of studies to show how and what children learn about science when they engage in designing technology activities (e.g., Roth 1995, 1996a, b, 1998; Roth et al. 1999). Based on his research, Roth (2001) concluded that designing technology activities impact the students' learning of science in so many ways. Roth stated that when students designed and constructed technology, they made their ideas "inspectable and arguable" (p. 776). The design drawings helped them communicate their ideas to their peers and opened them for their critique and inspection thus served in holding the students accountable for their ideas. Also, Roth found that the materials that were used to construct the technological artifacts served as an additional dimension of communication that students could utilize until they became more familiar with the scientific concepts involved in their designs and were more able to discuss them verbally. It is noteworthy that this was of particular importance to students who lacked the vocabulary and verbal fluency to communicate science concepts. This demonstrates that designing artifacts allow these students to participate in the classroom and take a role in the discussion in a non-verbal form until they develop the scientific discourse that allow them to discuss their science concepts verbally.

Roth (2001) observed that through designing technological artifacts, students were able to turn their ideas from a vague form, that can be verbal, to a concrete form that is situated in the environment. He called that process "thinking in the world" (p.778). He also called the process the "externalization of ideas" (p. 778). Through constructing the design artifacts, students made decisions that were based on their conceptual knowledge. This design process afforded them opportunities to examine their knowledge and become closer to their ideas (Roth 1996a, b). Roth (2001) elaborated on the significance of that process to the students' learning: “ Design artifacts allow an externalization of ideas; externalization makes ideas concrete and accessible. Design artifacts therefore constitute starting points for critical reflection and a rich ground for even more ideas" (p. 778). Thus indicating the importance of hands-on design as being critical in the formulation of conceptual understanding of abstract science ideas.

Roth (2001) also argued that designing technology activities "inherently makes available activity structures recommended by constructivist educators" (p. 781). He stated that when students are asked to develop their design ideas, "the lessons automatically start at developmentally appropriate points for each student" (p. 781). This is unlike traditional classrooms where it is difficult for the teacher to find out the level at which each student stands and determine whether he or she is ready to comprehend a certain science concept. Roth also concluded that since designing technology depended on students' ideas, it enriched their sense of ownership and developed their intrinsic motivation. 
Researchers have studied the nature of the community that emerges in the Design and Technology classroom (e.g., Brown et al. 1989; Lave and Wenger 1991; Roth 1995). The most important feature of the design and technology classroom is that learning revolves around action and hence, they are called "a community of practice" (Roth 1995, p. 475). Within such a community, learning is affected by the common task of its members, by the resources they share and by the practices they are associated with (Brown et al. 1989). In this community, students display evidence of learning by acquiring shared (linguistic) conventions, standards, behaviors, and view-points (Roth, p. 475).

Researchers tried to understand the nature of knowing and learning that occurs in the Design and Technology classroom (e.g., McGinn et al. 1995; Roth 1995). They tried to categorize the types of knowledge that are shared by the members of the community. According to Roth (1995), in the Design and Technology classroom, this knowledge "is constituted by the material, social, and conceptual resources available to individual members working alone or collaboratively and by the common embodied laboratory and discourse practices displayed by members during their tasks" (p. 476). Resources in the Design and Technology classroom include "facts, artifacts, formal rules for doing things, and heuristics" (p. 476). Practices exist as (a) tool-related practices and include "all those human practices that involve manipulating tools, and deploying materials" (McGinn et al. 1995, p. 164) such as operating a glue gun, sowing, and hammering and (b) discursive practices which are associated with conceptual knowledge and can be displayed as "doing a conceptual analysis of a pulley system, configuring drawings to analyze various ways of using a pulley, or providing a verbal description and explanation of the forces in a pulley system" (Roth 1995, p. 164).

Research has shown that the "diffusion of knowledge" (Roth 1995, p. 481), or the spread of knowledge, among the students in the Design and Technology classroom was related to the type of knowledge and to the person who introduced the knowledge. Roth (1995) observed that students easily shared resources (facts, ideas, and artifacts). On the other hand, "discursive practices were much less widely appropriated" (p. 164). For example, students were easily able to know the name of the product moment rule which is used to solve a problem related to a balance beam (a resource) "but faced more difficulty in deploying the rule to get the problem done (discursive practice)" (p. 164). Also, McGinn et al. (1995) observed that "knowledge introduced by the teacher was less appropriated by the community than knowledge introduced by a student" (p. 175). This implies the need for promoting collaborative learning in the design and technology classroom where students can learn from each other.

Hennessy and Murphy (1999) conducted a 3-year study of problem solving in Design and Technology workshops in schools and were able to conclude that the Design and Technology activity provided a rich environment that supported collaborative learning. However, such collaborative learning, although anticipated, was seldom supported by teachers and rarely observed by researchers (Murphy and Hennessy 2001). Murphy and Hennessy (2001) embarked on looking closer into that aspect of Design and Technology. Their study yielded evidence of effective collaboration amongst the students at the early stages of design. As the design process progressed, the collaborative efforts of the students were undermined. Murphy and Hennessy observed that students were able to collaborate at the beginning without the support of the teacher. As the design process progressed, their collaboration efforts collided with the teachers' views on their learning needs and class organization.

Murphy and Hennessy (2001) have shown that there were a lot of lost opportunities for successful collaboration in the design and technology classroom. Teachers lacked the 
understanding of collaboration as a learning mechanism. Students lacked the social skills and some of the cognitive strategies for collaboration. The team work was valued but not prioritized, thus, some students were allowed to work individually. The need to meet a certain deadline for delivering the finished product put a strain on the teacher and pushed him to take control of the classroom at certain times, hence, "the teacher was not able to shift the locus of control toward the students" (p. 214).

For a successful design and technology activity, teachers need to acquire more understanding of their role as supporters of collaborative learning in the classroom. Teachers need to shift the locust of control towards the students and function as a peer, moderator and facilitator (Johnson 1997). Teachers need to scaffold the students' effort to collaborate but they should be sensitive to the students' need and know when to intervene and when to hold back. Murphy and Hennessy call that "sensitive assistance" (p. 205).

\section{Technology education and the process of designing technology}

The immaturity of research related to understanding technological knowledge has affected technology education. Unlike science education which is a well established discipline, technology education is "still in its infancy as a subject" (McCormick 1997, p. 141). Consequently, there has been a lack of a developed research base on pedagogical strategies to teach technology compared with science or mathematics (Jones 1997). This lack of research on pedagogical strategies combined with a complex nature of knowledge with a definition and understanding that is still evolving, has created a challenging situation for technology educators.

One of the challenges that faced technology education was its struggle to strike a balance between concept and process. Technology educators divided technology knowledge into two categories, conceptual knowledge and procedural knowledge or what they called 'knowing that' and 'knowing how' (Ryle 1949 as cited in McCormick 1997). Because of the history of technology education as "a craft, skills-oriented school activity" (De Vries and Tamir 1997, p. 4) technology education curriculum focused on procedural knowledge while conceptual knowledge was neglected.

This debate of content verses process was not unique to technology education. Other mature disciplines had similar debates such as the debate of real science versus school science in science or the debate of 'skills versus understanding' in mathematics or 'whole language versus phonetic' in language (McCormick 1997). However, unlike science education that was trying to break from a content-laden curriculum that promoted 'pure science' as a dominant category detached from practical context since the second half of the 19th century (Layton 1991), technology education was moving in the opposite direction, away form process-based curriculum and towards a more balanced curriculum that did not ignore content but still favored process (McCormick 1997).

According to McCormick (1997), technology education curricula focused on process because procedural technological knowledge appeared to be easier to define than conceptual technological knowledge. This led to technology education curricula that focused on processes such as design and problem solving. However, the process that constituted the underpinning structure of technology education was: design (Mawson 2003). Technology education curricula in England, Wales, Australia, New Zealand and the United States, are all to a varying degree based on "designing" and "making" (Mawson). The problem with these curricula, Mawson argued that they used a "design process paradigm" that was "fatally flawed" (p. 117). 
The first flaw with technology education curricula was that they teach design as a linear process. Johnsey (2000) reviewed 17 different attempts at defining the design process models in England between 1971 and 1995. His review revealed that all models displayed a linear, simplistic and inaccurate representation of what really takes place when students engage in the design process. Looking at how the design process is identified in the technology education curriculum in the United States, reveals the same pattern. For example, according to the Massachusetts Department of Education (MassDoE), design is represented by eight cyclical steps (MassDoE, May, 2001, p.73).

Johnsey (2000) challenged this linear step-like, iterative process and argued that it did not describe what occurred when students designed technology. By observing students through the design process, Johnsey concluded that when primary-age children design they do not "conform to a neat pattern or sequence of actions" (p. 21). Instead, Johnsey was able to identify eleven "behavioral descriptors or designing and making skills" (p. 17) that students displayed during the design process. The students used these skills over and over again in no particular order which gave evidence to the "untidy nature of designing and making" (p. 20).

By observing professional designers and children in the classroom, researchers (e.g., Barlex et al. 2001; Hill and Anning 2001a, b; Roberts et al. 1999, as cited in Mawson 2003) concluded that "neither students nor designers naturally utilize a predetermined process in their work, instead they invent a process as they proceed toward task completion" (Mawson, p. 120). The findings of this research and other research studies (e.g., Johnsey 2000; McCormick et al. 1993) led the researchers to reject the validity of the linear model of the design process. However, teachers of technology education persisted in adhering to it in their teaching (Mawson 2003). The reason for this, Mawson writes "was to make possible the teaching and assessing of technology education by imposing order on what is an essentially confused iterative process" (p. 199). Meaning that, to present teachers with a structured framework of design that is easier to teach and manage, curriculum developers adopted a simplistic model that was closer to 'myth' than reality because the reality is that design does not and probably has never taken place in a linear manner (Roberts and Norman 1999, as cited in Mawson 2003).

The major limitation of teaching design as a linear systematic process that can be taught and learned by all students who can then apply it to subsequent problems and situations, is the inherent contextual nature of design. Drawing on the research conducted by cognitive psychologists, the importance of context for the application of knowledge and skills have been recognized and demonstrated empirically (Hennessy and McCormick 1994). Such research has been of great implications for technology education, a discipline that revolves around the practical, because of its focus on the relationship between cognition and action. Based on that research, cognitive psychologists developed learning theories that went under many names such as “ “every day cognition' (Rogoff and Lave 1984), 'cognition in practice' (Lave 1988) and 'every day understanding' (Semin and Gregen 1990)" (Layton 1991, p. 65), but all agreed on their emphasis on the importance of context for cognition.

Based on following people in various spheres of life and studying the way they think, these studies concluded that "context is intricately interwoven with the problem to be solved" (Rogoff and Lave, p. 2, as cited in Layton 1991). In everyday life, people were able to device satisfactory solutions to their problems that adjusted to meet the demands of the situation and hence giving evidence to the fact that thinking is a practical activity (Rogoff and Lave, as cited in Layton). In the accounts of the practice of design, there is evidence that parallels these findings; "namely that objects, tools, solutions and problems all interact to determine design thinking" (McCormick 1997, p. 151). 
This research has many implications for teaching design. One implication is that there is no disjunction between theory and practice and hence, procedural knowledge cannot be taught in isolation from conceptual knowledge. It is conceptual knowledge that makes possible the use of procedural knowledge (McCormick 1997). In a study that looked into how novices and experts approached mechanical problems, the experts showed better performance. "The better performance of the experts was attributed to their deeper conceptual understanding of physics principles" (Chi et al. 1981, as cited in Johnson 1997, p. 164).

Science concepts constitute one part of conceptual knowledge. Without the knowledge of these science concepts, students will not be able to design technology that draws on these concepts. However, it is also important to teach the students the other components of conceptual knowledge that are essential for their ability to design. Knowledge of functional rules such as how to operate a drilling machine or even a glue gun could prove to be as essential to the design process as science concepts. Also, students have to be taught about the properties of materials available and the processes they have to follow in order to prepare these materials before using them in their design. In essence, the conceptual knowledge that the students need to acquire in order to design a certain technological artifact has to be identified and taught to the students.

Besides conceptual knowledge, students will need to acquire certain technical skills that are utilized during their design tasks. These technical skills have to be identified and their learning planned at an appropriate time during the design process (Mawson 2003). Technical skills have to be taught in action and have to be modeled by the teacher or an expert or a fellow student.

The emphasis of cognitive learning theories on context also implies that design cannot be taught as a general process that is transferable to any situation. Although it is acceptable that teachers present to the students a general model of design as an introduction to teaching this process, it is important to explicitly give them examples from several fields of technology (e.g., food, textile) where the design process does not follow this general process (McCormick 1997). It is also important to explain that they are not expected to follow that general model but to move freely between phases of design as they see appropriate. Research showed that when students were allowed to choose their own pathway to begin the design process, their choices varied. One choice was to begin by exploring the materials and tools available to them (Anning 1997a; Hope 2000, as cited in Mawson 2003).

Because design is context dependent, Mawson (2003) emphasized the need to give the students time "to immerse themselves in the context of the task" (p. 123) prior to posing the specific design problem. Research has shown that this increased the range and appropriateness of the solutions the students developed (Video Campus 2001, as cited by Mawson).

Besides teaching conceptual knowledge and procedural knowledge, McCormick (1997) stressed the need for teaching 'strategic knowledge' to the students. He defined strategic knowledge as a 'how-to-decide-what-to-do-and-when' knowledge, (p. 145). He saw the need for teaching strategic knowledge as parallel to the call for teaching students the strategies of metacognition which helps the students take control of their own learning. In essence, McCormick called for laying the control of the design process in the hand of the students. To aid the students in achieving this control, he advised the teachers to explicitly teach every step of the design process and model it to the students. He stressed that "only by explicit teaching of how and when to employ procedures can this strategic knowledge be developed, and importantly, be transferred to new situations" (p. 147). Research has 
shown that teachers rarely modeled designing processes for the students. Because of this lack of explicit teaching, students went through the design task without awareness or understanding of this process (Hennessy and McCormick 1994).

Teaching strategic knowledge by adopting explicit teaching strategies and encouraging the students to continuously reflect on their learning is believed to enhance 'knowledge transfer' Knowledge transfer is the ability to acquire knowledge in one context and apply it in another (Johnson 1997). Because designing technology draws into many disciplines, teaching design can be intertwined with teaching science. It can also be intertwined with teaching other subjects such as mathematics and social studies. In order to teach science by designing technology the designing task has to 'make use' of the science concepts (Johnsey 2000). However, before science concepts can be useful in designing technology, they have to be reshaped and reconstructed (Layton 1991). For example, the concept of 'resistance' as it is introduced in the science classroom through investigating wires of different lengths and thicknesses may not be functional in the context of designing technology where ceramic resistors all look alike (McCormick 1997).

\section{Knowledge transfer and teaching science through designing technology}

Knowledge transfer constitutes a challenge and a promise in technology education. Designing technology provides the opportunity to help students enhance their knowledge transfer skills. On the other hand, the inability of students to transfer their knowledge from other disciplines such as science and mathematics hindered their ability to design (Hennessy and McCormick 1994). Johnson (1997) conducted an extensive review of the literature related to the issue of knowledge transfer. Based on his review, Johnson concluded that knowledge transfer depends on the depth of learning (Perkins and Salomon 1988, as cited in Johnson). He explained that deep conceptual understanding of the knowledge would enable the learner to look beneath the surface structure and recognize the abstract rules that apply in other situations. Also, to enhance knowledge transfer, he stressed the need to teach the students 'conditionalized knowledge.' He defined conditionalized knowledge as the knowledge about the conditions under which knowledge is applicable (Simon 1980, as cited in Johnson). Johnson contended that knowledge does not transfer easily because students may learn how to perform a strategy but they do not learn when it is appropriate to use it. This emphasizes the need to teach design within a context and to help the students understand that different contexts may require certain adjustments to the design process. This may enhance their ability to transfer their design skills from one context to another.

\section{When teaching science through designing technology, what is taught first, science or technology?}

When teaching science through designing technology, the question arises on what to present first to the students, science or design. Johnsey (2000) stressed first on the need for applying the appropriate pedagogy to teach each discipline. Science needs to be taught and technology needs to be taught. In his research studies he introduced students to the design task at the beginning and the students were given almost formal science lessons in parallel to the design project. The teachers he interviewed reported that students showed more interest in learning the science because they wanted to apply it in their design. These 
findings are in parallel to observations of other researchers (e.g., Hennessy and McCormick 1994; Roth 2001) who noticed how students gained knowledge by responding to problems and dilemmas they faced in their design. In his study on teaching a civil engineering unit to elementary students, Roth observed that most students adopted the principle of bracing in their bridge design in response to failure of their bridges not in response to the teacher's efforts to encourage them to do so.

Introducing the design task to the students at the beginning is also supported by the cognitive theories that I discussed earlier that stress the link between context, action, content and cognition. The potential of teaching science through designing is that the design task provides the context for applying the science knowledge and the science concepts provide a part of the content needed for performing the design task.

Despite the implications of these research studies that students need to be introduced to the design task at the beginning and then learn the science in parallel lessons, the findings of these studies were not conclusive and the issue has not been addressed in them directly. In the science scope and sequence developed by the Philadelphia School District for grades $5-8$, the recommendation is to teach the science unit first to the student and to use the design process as an assessment tool of science knowledge at the end of teaching the unit (School District of Philadelphia 2002). The problem with this format is that it is built on the assumption that science concepts represent the only knowledge needed for design. It neglects the need for teaching the other components of technological knowledge and ignores the fact that the design process itself also needs to be taught to the students and cannot be used merely as an assessment tool.

\section{Summary}

The review of the literature provides insight and guidelines for teaching science through designing technology. This is a summary of these guidelines:

1. Students have to be aware that design is a context specific process and that there is no general design process that can be applied to all contexts. To understand this concept, the students have to be exposed to designers from various fields of technology such as food industry, textile or auto making. Expert designers from these fields can visit the students in their school or the students can go on field trips to visit these designers in their work environment.

2. Because design is context dependent, students should be given time to immerse themselves in the context of the design task prior to posing the specific design problem. This can be achieved by providing the students with some time to conduct some research and brainstorming related to the field of the design task. Also, the visits by the experts in the field or the field trips can serve the purpose of immersing the students in the context of the problem.

3. Students can be taught a general linear model of design as an introduction to teaching this process, but they have to be told that they are not obligated to adhere to that linear model when they design. Based on the problems they face and as they solve them, their process of design can take any shape or form. For example, the technology teacher should not insist that all students start with providing a drawing of their design at the beginning of the design process. The teacher should offer several starting points of the design process. Some students may prefer to start 
designing by exploring the available materials and tools others may start with evaluating an existing design in order to improve on it.

4. In order to be able to design a technological artifact, the students should be taught the conceptual and procedural knowledge entailed in producing that design. Theory and action go hand-in-hand and cannot be separated. It is only with a strong conceptual background that students would be able to apply their procedural knowledge to produce a successful design.

5. Science concepts constitute a part of the conceptual knowledge needed for designing technology. Other components of conceptual knowledge such as empirical generalizations or machine operational chart reading should be identified and taught to the students.

6. Students may not be able to apply the science concepts they learn in the science classroom when they design technology. Students may need the teacher's support to be able to transfer their knowledge from the science classroom to the Design and Technology classroom.

7. Besides conceptual knowledge, students need procedural knowledge or technical skills to be able to design technology. These technical skills have to be identified before hand and then taught to the students. Technical skills have to be taught in action and the technology teacher, an expert or a fellow student have to model them to the students.

8. Besides teaching conceptual knowledge and procedural knowledge, students will need to be taught strategic knowledge or 'how-to-decide-what-to-do-and-whenknowledge.' Strategic knowledge have to be taught by explicit teaching of every step of the design process.

9. The potential of teaching science through designing technology is that the design task provides the context for applying the science knowledge and the science concepts provide a part of the content needed for performing the design task.

10. Although the Design and Technology classroom provides great opportunities for collaboration among students, this collaboration does not happen automatically. The teachers have to be trained to provide the environment that fosters collaborative learning.

\section{References}

American Association for the Advancement of Science. (1989). Science for all Americans. New York: Oxford University Press.

American Association for the Advancement of Science (AAAS). (1993). Benchmarks for science literacy. New York: Oxford University Press.

Brown, A. L. (1992). Design experiments: Theoretical and methodological challenges in creating complex interventions in classroom settings. The Journal of The Learning Sciences, 2(2), 141-178.

Brown, J. S., Collins, A., \& Duguid, P. (1989). Situated cognition and the culture of learning. Educational Researcher, 18, 32-42.

Cajas, F. (2001). The science/technology interactions: Implications for science literacy. Journal of Research in Science Teaching, 38(7), 715-729.

Carraher, T. N., Carraher, D. W., \& Schliemann, A. D. (1985). Mathematics in the streets and in school. British Journal of Developmental Psychology, 3, 21-29.

Crismond, D. (2001). Learning and using science ideas when doing investigate-and-redesign tasks: A study of naive, novice, and expert designers doing constrained and scaffolded design work. Journal of Research in Science Teaching, 38(7), 791-820.

De Vries, M. J. (1997). Science, technology and society: A methodological perspective. International Journal of Technology and Design Education, 7, 21-32. 
De Vries, M. J., \& Tamir, A. (1997). Shaping concepts of technology: What concepts and how to shape them. International Journal of Technology and Design Education, 7, 3-10.

Edelson, D. C. (2001). Learning for use: A framework for the design of technology-supported inquiry activities. Journal of Research in Science Teaching, 38(3), 355-385.

Gardner, P. L. (1997). The roots of technology and science: A philosophical and historical view. The International Journal of Technology and Design Education, 7, 13-20.

Hansen, R. (1997). The value of a utilitarian curriculum: The case of technological education. International Journal of Technology Education and Design Education, 7, 111-119.

Hennessy, S., \& McCormick, R. (1994). The general problem-solving process in technology education. Myth or reality? In F. Banks (Ed.), Teaching technology (pp. 94-108). London: Routledge.

Hennessy, S., \& Murphy, P. (1999). The potential for collaborative problem solving in D\&T. International Journal of Technology and Design Education, 9(1), 1-36.

Johnsey, R. (2000). Identifying designing and making skills and making cross curricular links in the primary school. In J. Eggleston (Ed.), Teaching and learning design and technology (pp. 15-33). London and New York: Continuum.

Johnson, S. (1997). Learning technological concepts and developing intellectual skills. International Journal of Technology and Design Education, 7, 161-180.

Johnson, D. W., \& Johnson, R. T. (1991) Learning together and alone (3rd ed.). Englewood Cliffs, NJ: Prentice Hall.

Jones, A. (1997). Recent research in learning technological concepts and processes. International Journal of Technology and Design Education, 7, 83-96.

Kolodner, J. L. (2002). Facilitating the learning of Design practices: Lessons learned from an inquiry into science education. Journal of Industrial Teacher Education, 39(3), 9-40.

LaPorte, J. E., \& Sanders, M. E. (1993). The T/S/M integration Project. Integrating technology, science, and mathematics in the middle school. The Technology Teacher, 52(6), 17-21.

Lave, J. (1988). Cognition in practice. Boston, MA: Cambridge.

Lave, J., \& Wenger, E. (1991). Situated learning: Legitimate peripheral participation. Cambridge, UK: Cambridge University Press.

Layton, D. (1991). Science education and praxis: The relationship of school science to practical action. Studies in Science Education, 19, 43-79.

Layton, D. (1993). Technology's challenge to science education: Cathedral, quarry or company store? Open University Press: Buckingham, Philadelphia.

Massachusetts Department of Education. (2001). Massachusetts science and technology/engineering curriculum framework, May 2001. Retrieved April 15, 2002, from http://www.doe.mass.edu/ frameworks/current.html

Mawson, B. (2003). Beyond 'the design process': An alternative pedagogy for technology education. International Journal of Technology and Design Education, 13, 117-128.

McCormick, R. (1997). Conceptual and procedural knowledge. The International Journal of Technology and Design Education, 7, 141-159.

McCormick, R., Hennessy, S., \& Murphy, P. (1993). A pilot study of children's problem solving processes. In J. S. Smith (Ed.), IDATER 93, Loughborough: Design and Technology (pp 8-12). Loughborough University.

McGinn, K. M., Fraser, S., \& Roth, W.-M. (1998). Assessing students' understanding about levers: Better test instruments are not enough. International Journal of Science Education, 20(7), 813-832.

McGinn, K. M., Roth, W.-M., Boutonne, S., \& Wosczczyna, C. (1995). The transformation of individual and collective knowledge in elementary classrooms that are organised as knowledge-building communities. Research in Science Education, 25(2), 163-189.

Murphy, P., \& Hennessy, S. (2001). Realising the potential - and lost opportunities - for peer collaboration in a D\&T setting. International Journal of Technology and Design Education, 11, 203-237.

Research Council. (1996). National science education standards. Washington, DC: National Academy Press.

Qualification and Curriculum Authority. (2001). Design \& technology: Progression in design and technology. In National curriculum in action. Retrieved from http://www.ncaction.org.uk/subjects/ design/progress.htm

Roazzi, A., \& Bryant, P. (1992). Social class, context and cognitive development. In P. Light \& G. Butterworth (Eds.), Context and cognition: Ways of learning and knowing. Hemel Hempstead: Harvester, Wheatshaeaf.

Rogoff, B., \& Lave, J. (1984). Everyday cognition: Its development in social context. Cambridge, MA: Harvard University Press. 
Roth, W.-M. (1995). Inventors, copycats, and everyone else: The emergence of shared resources and practices as defining aspects of classroom communities. Science Education, 79, 475-502.

Roth, W.-M. (1996a). Art and artifact of children's designing: A situated cognition perspective. The Journal of the Learning Sciences, 5, 129-166.

Roth, W.-M. (1996b). Knowledge diffusion in a grade 4-5 classroom during a unit on civil engineering: An analysis of a classroom community in terms of its changing resources and practices. Cognition and Instruction, 14, 179-220.

Roth, W.-M. (1998). Designing communities. Dordrecht: Kluwer Academic Publishing.

Roth, W.-M. (2001). Learning science through technological design. Journal of Research in Science Teaching, 38(7), 768-790.

Roth, W.-M., McGinn, M. K., Woszczyna, C., \& Boutonne, S. (1999). Differential participation during science conversations: The interaction of focal artifacts, social configuration, and physical arrangements. The Journal of the Learning Sciences, 8, 293-347.

Rowell, P. M., Gustafson, B. J., \& Guilbert, S. M. (1999). Characterization of technology within an elementary science program. International Journal of Technology and Design Education, 9, 37-55.

Scardamalia, M., \& Bereiter, C. (1994). Computer support for knowledge-building communities. The Journal of the Learning Sciences, 3, 265-283.

School District of Philadelphia. (2002). Science scope and sequence. Philadelphia, Pennsylvania: Author.

Seiler, G., Tobin, K., \& Sokolic, J. (2001). Design, technology, and science: Sites for learning, resistance, and social reproduction in urban schools. Journal of Research in Science Teaching, 38(7), 746-767.

Semin, G. R., \& Gergen, K. J. (1990). Everyday understanding: Social and scientific implications. London: Sage Publication.

Sorrohan, E. G. (1993). We do therefore we learn. Learning \& Development, 47(10), 47-55.

Stein, S., McRobbie, C., \& Ginns, I. (2002). Implications of missed opportunities for learning and assessment in design and technology education. Teaching and Teacher Education, 18(1), 35-49. 